\title{
Vertebral morphology, dentition, age, growth, and ecology of the large lamniform shark Cardabiodon ricki
}

Michael G. Newbrey, Mikael Siversson, Todd D. Cook, Allison M. Fotheringham, and Rebecca L. Sanchez

Acta Palaeontologica Polonica 60 (4), 2015: 877-897 doi: http://dx.doi.org/10.4202/app.2012.0047

Cardabiodon ricki and Cardabiodon venator were large lamniform sharks with a patchy but global distribution in the Cenomanian and Turonian. Their teeth are generally rare and skeletal elements are less common. The centra of Cardabiodon ricki can be distinguished from those of other lamniforms by their unique combination of characteristics: medium length, round articulating outline with a very thick corpus calcareum, a corpus calcareum with a laterally flat rim, robust radial lamellae, thick radial lamellae that occur in low density, concentric lamellae absent, small circular or subovate pores concentrated next to each corpus calcareum, and papillose circular ridges on the surface of the corpus calcareum. The large diameter and robustness of the centra of two examined specimens suggest that Cardabiodon was large, had a rigid vertebral column, and was a fast swimmer. The sectioned corpora calcarea show both individuals deposited 13 bands (assumed to represent annual increments) after the birth ring. The identification of the birth ring is supported in the holotype of Cardabiodon ricki as the back-calculated tooth size at age 0 is nearly equal to the size of the smallest known isolated tooth of this species. The birth ring size (5-6.6 mm radial distance [RD]) overlaps with that of Archaeolamna kopingensis (5.4 mm RD) and the range of variation of Cretoxyrhina mantelli (6-11.6 mm RD) from the Smoky Hill Chalk, Niobrara Formation. The revised, reconstructed lower jaw dentition of the holotype of Cardabiodon ricki contains four anterior and 12 lateroposterior files. Total body length is estimated at $5.5 \mathrm{~m}$ based on $746 \mathrm{~mm}$ lower jaw bite circumference reconstructed from associated teeth of the holotype.

Key words: Lamniformes, Archaeolamna, Squalicorax, vertebral centra, Cretaceous, Cenomanian, Turonian, Australia.

Michael G. Newbrey [newbrey_michael@columbusstate.edu], Royal Tyrrell Museum of Palaeontology, Drumheller, Alberta T0J 0Y0 Canada; current address: Department of Biology, Columbus State University, Columbus, Georgia 31907, USA; Mikael Siversson [mikael.siversson@museum.wa.gov.au], Department of Earth and 
Planetary Sciences, Western Australian Museum, 49 Kew Street, Welshpool, Western

Australia; Todd D. Cook [tdc15@ psu.edu], Department of Biological Sciences, University of Alberta, Edmonton, Alberta T6G 2E9 Canada; current address:

School of Science, Penn State Erie, The Behrend College, Erie, Pennsylvania

16563, USA; Allison M. Fotheringham [lunavallis@yahoo.ca] and Rebecca L.

Sanchez [rbbsanchez@gmail.com], Royal Tyrrell Museum of Palaeontology, Drumheller, Alberta T0J 0Y0 Canada.

This is an open-access article distributed under the terms of the Creative Commons

Attribution License (for details please see creativecommons.org), which permits unrestricted use, distribution, and reproduction in any medium, provided the original author and source are credited.

FaF Full text $(10,131.0 \mathrm{kB})$ 